\title{
Research on Agricultural Products Circulation Model and Countermeasures under the Background of Electronic Commerce
}

\author{
Liu Jingjing \\ Business School \\ Wuhan Polytechnic \\ Wuhan, China \\ 31909078@qq.com
}

\begin{abstract}
Circulation of agricultural products is vital to the national economy and people's life. The rapid development of e-commerce has injected new vitality into the circulation of agricultural products. In order to promote the circulation efficiency of agricultural products in china, this paper analyzed the traditional and modern circulation model under the background of electronic commerce. This paper summarized modern circulation model into four models, that enterprise self-built website direct sales model, network information platform model, specialized e-commerce trading platform model and integrated supply chain sales model. After described the advantages and disadvantages of the four circulation models under the background of electronic commerce, against their disadvantages, this paper put forward the countermeasures for the efficient circulation of agricultural products. The countermeasures are from the government, enterprises, supply chain and the Internet of things aspects, they are practical and comprehensive, can promote the circulation of agricultural products in China and optimize the distribution of agricultural products in China.
\end{abstract}

Keywords-E-Commerce; Agricultural Products; Circulation Model; Countermeasures

\section{INTRODUCTION}

Agriculture is the basic industry of the national economy, and the agricultural products are closely related to the life of every one of us. Efficient circulation of agricultural products is an important guarantee for consumers to get the product. Because agricultural products are not easy to store, easy to decay and seasonal characteristics, especially fresh agricultural products, shelf life is short, the need for special packaging, circulation conditions and distribution equipment, but consumers need fresh, healthy, inexpensive agricultural products, which makes the circulation of agricultural products and general industrial products have a big difference, the distribution of agricultural products more emphasis on efficient and safe, and also pay more attention to how to reduce loss, reduce costs.

\section{THE TRADITIONAL CIRCULATION MODE OF AGRICULTURAL PRODUCTS IN CHINA AND ITS DISADVANTAGES}

Our traditional agricultural products logistics have too more sectors, products produced by the farmers or agricultural products processing enterprises, usually need to enter the wholesale market, after the origin of the wholesale market, than it transits to second hand wholesalers or retailers before circulate to final consumer.

There are many problems in the traditional circulation mode, which is a long way, the backward of transportation equipment and the fresh keeping technology, the heavy loss of the way, the higher the circulation cost. Relevant data show that China's agricultural products in the transport process, the loss about $25 \%-30 \%$, far more than $3 \%-5 \%$ of the European and American countries. This distribution pattern, which leads to the large price difference between the sales price and the purchase price, will lead to low economic efficiency, is not conducive to the sustainable development of China's agricultural products [1].

\section{TYPICAL MODELS OF AGRICULTURAL PRODUCTS CIRCULATION UNDER THE BACKGROUND OF ELECTRONIC COMMERCE}

The rapid development of electronic commerce has widened the agricultural products information and sales channels, brought agricultural products new trade and circulation pattern. Under the background of e-commerce, agricultural products circulation pattern mainly has the following four types:

\section{A. Enterprise Self-Built Website Direct Sales Model}

Under this model, farmers, agricultural products bases or agricultural products processing enterprises, through the establishment of their own website, publish product information, do the transaction with the customers. After the purchase, seller will deliver goods through the third party logistics or self-built logistics.

For the buyer, they can contact the manufacturer directly, product traceability easy, product quality is 
guaranteed, and the price is relatively low. But for the seller, not only need to self-built website (or online shop), but also need timely release information, and doing business electricity, it is a large investment and cost a lot of energy, it is not suitable for many small and medium farmers or enterprises.

\section{B. Network Information Platform Model}

Under this model, the agricultural product electronic commerce enterprises or other institutions set up Website, and timely release of agriculture related information, such as market information, supply and demand information, prices, business information and contact, market distribution, government regulations.

The supplier and demander find the information they needed, and will contact each other based on the contact information on the website, negotiate business and trade.

Under this model the circulation is also through the traditional channels, the website only plays a role in the information dissemination. This model cannot increase the trust between buyers and sellers cannot effectively improve the success rate of transactions.

\section{Specialized E-Commerce Trading Platform Model}

Agricultural products circulation model under the third party e-commerce platform is shown in Figure 1.

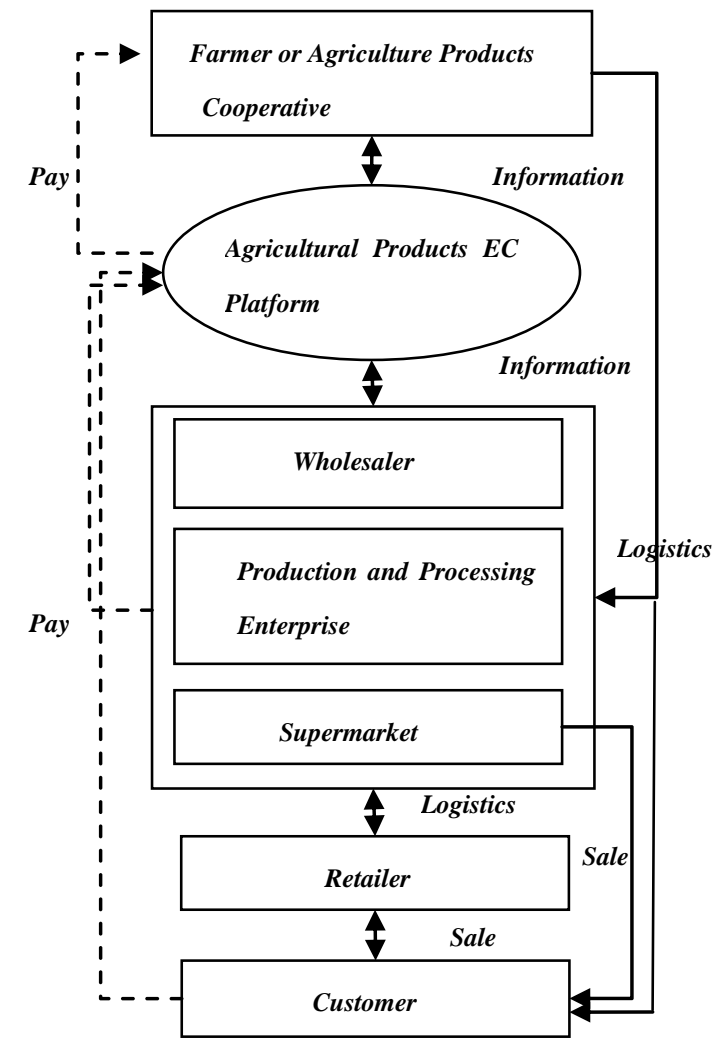

Figure1. Agricultural Products Circulation Mode Under the Third Party E-Commerce Platform [2]

In this model, the network platform is established by the professional electronic commerce enterprise, farmers or agricultural products production enterprises will put the products information on the platform for online sales. This model uses online payment. The buyer and seller trade freely, and mostly through the third party logistics to distribution, the platform itself is not directly involved in the transaction, but as a third party to charge a transaction fee or advertising fee, pay margin and technical services, to provide users with professional services.

This model mainly has the following three different sales types:

1) B2C (Business-to-Customer) retail model: $\mathrm{B} 2 \mathrm{C}$ is an abbreviation for Business-to-Customer, which is a commercial retail model for the consumers to sell goods and services through the electronic commerce platform and typical B2C business platform such as Taobao.com, tmall.com, yhd.com, etc.

Typical cases such as online supermarket "yhd.com" and Tongyu County, Jilin Province, signed origin direct sales strategic cooperation contract. The two sides through the professional e-commerce platform for cooperation, the preferred agricultural products produced in the Tongyu County, sale to all parts of the country through the "yhd.com" high-quality electricity supplier channel.

2) B2B bulk agricultural products online trading model: $\mathrm{B} 2 \mathrm{~B}$ is the abbreviation of Business-to-Business, refers to the business between the enterprises sales, this model is the use of electricity business platform, to trade the bulk of agricultural products. Typical network platform such as China's Green Valley Network (www.2565cn.com), China's Green Valley network is invested and built by Brent group, the platform mainly consists of three parts: agricultural product information release platform, online trading platform, logistics information publishing platform, it can provide all kinds of agricultural products such as vegetables, fruit, livestock, aquatic products, grain and oil, non-staple food, dry goods commodities trading.

3) $\mathrm{O} 2 \mathrm{O}$ circulation model: $\mathrm{O} 2 \mathrm{O}$ is the abbreviation of Online to Offline. Under this circulation mode, agricultural products, farmers, agricultural products base or agricultural products processing enterprises, etc., direct sale their products through the establishment of chain stores, direct sales outlets. At the same time, the development of online e-commerce platform, mobile APP, and its combination with the line of agricultural products retail enterprises, customers can buy online, pay online and take goods in the direct store.

The advantages of this model are: for the seller, they do not need to build their own websites, the cost of building their online store on the platform can be lower than self-built websites, but also can share the e-commerce platform customer groups.

For the buyer, the e-commerce platform will gather a number of suppliers and their product information, including the supplier reputation level, product quality certification, customer feedback, etc., to facilitate the buyer's finding information, understanding and comparison.

In terms of payment, the platform can play a role in the credit guarantee. The buyer's payment is not directly pay to the seller's account but first pay to the third party depository account, after the buyer received the goods and confirmed, the third party depository accounts pay to the seller, thereby eliminating distrust between the seller and buyer on the purchase.

The platform can also have the function of quality supervision, through the quality testing of signing farmers' 
products, allowing qualified agricultural products to sale [2].

The disadvantages of this model are: logistics cost is high, the resources integration degree is low, the efficiency of logistics distribution, especially the quality and efficiency of cold chain logistics, directly determines the success or failure of this way.

\section{Integrated Supply Chain Sales Model}

Under this model, the core enterprise in the supply chain of agricultural products, through the integration of resources, will integrate purchase, storage, distribution and network marketing, after-sales, and then add the quality certification, certificate of origin, to establish agricultural products supply chain, to obtain customer orders through e-commerce platform or mobile phone APP, to provide consumers integrated sales and service.

The typical representative of this model is justeasy.com-a fresh supermarket online in Wuhan. Hongbo Group invested 50 million established this modern agricultural science and technology company. It is based on the family fresh agricultural products supply, justeasy.com company constructs the B2C e-commerce platform, from agricultural planting and harvesting, sorting and processing, storage and distribution process, self-built the throughout the cold chain logistics and distribution systems, installs self-stripping cabinet in hundreds of Wuhan city community, realized the "electricity +cold chain express logistics + intelligent terminal pickup" advanced business model, created a modern agricultural supply chain.

The advantages of this model are: for consumers, the source of agricultural products is clear, the quality of products is guaranteed, logistics services are in a timely manner, services are good. The disadvantages are: high cost of circulation, the company's cold chain equipment, the electricity business platform and even mobile terminals, are large investment. It has high requirements on enterprise resource integration and operational capacity. Some agricultural products are low profit, and the profit space of the enterprise is compressed.

\section{THE DEVELOPMENT STRATEGY OF EFFICIENT}

\section{CIRCULATION OF AGRICULTURAL PRODUCTS}

Compared with the traditional circulation pattern, the electronic commerce circulation pattern of agricultural products has more advantages: reduce the circulation link, shorten the circulation time, reduce the transaction cost, and overcome the problems that the information is not smooth, the sales information is out of line with the agricultural production. But there are also many deficiencies.

The shortcomings such as the coverage of electronic commerce circulation need to further improve, in circulation channels, high repetition rate, no special and stable supply of products, high circulation costs, the information degree is not high, especially agricultural e-commerce companies and upstream business communication. In the process of transportation, it is impossible to achieve tracking and so on [3].

The efficient circulation strategies of the agricultural products are as follows:

\section{A. The Government Should Play a Role in the}

\section{Circulation of Agricultural Products}

The government should actively formulate preferential policies to promote the development of agricultural e-commerce development, strengthen the social credit system, electronic payment and agricultural products online trading standards, to create a good environment for the development of e-commerce, improve the construction of agricultural products electronic commerce supporting system [4].

The government also should support the development of agricultural products cold chain logistics enterprises, foster the development of third party cold chain logistics, focus on cultivate a number of strong, potential, radiation driving ability agricultural products cold chain logistics leading enterprises.

The government need to strengthen the rural areas of the Internet infrastructure and supporting construction, training Internet talent of rural areas, integrated information service platform of rural areas, develop logistics and distribution services, so that link the advantages of rural resources and agricultural modernization in series [5-6].

The government also can build and improve the agricultural products logistics infrastructure, speed up the rural infrastructure, improve the rural transportation system, provide support for the agricultural products transportation system, encourage the logistics, express delivery company to extend to the countryside, to speed up the efficient circulation of agricultural products.

\section{B. The Enterprise Need to Form an Integrated Supply}

\section{Chain according to Market Demand}

Agricultural products are different with the industrial products, the industry chain is relatively long, and the sale is only a small part of the chain. The core enterprise in the supply chain of agricultural products plays a leading role. Forming an integrated supply chain according to market demand can help them to win market competition.

In the upstream, the integration of agricultural products production base, do not only stay in the direction procurement, but should be based on the strategic coordination of supply and demand, with the market orientation to guide the base have a plan to plant products.

In the downstream, the electronic commerce platform focuses on its core competitiveness to develop and service customers.

The core part of the chain joint upstream and downstream together, to speed up the flow of information flow, capital flow, logistics, and thereby reducing the cost of the whole chain of circulation, improve efficiency.

\section{The Parts in the Whole Supply Chain Need to} Implementation of Professional Division of Labor and Improve the Efficiency

1) Farmers or the agricultural products bases do professional production: In the supply chain of supply and marketing integration, the source is the farmers or the agricultural products bases, which is responsible for the production.

At the same time, strengthen the function of 
agricultural cooperatives. They can provide reliable information for the production of farmers. Help farmers to determine the type of production, production scale, improve product quality, to ensure product safety. At the same time, through the electronic commerce platform, for farmers to broaden sales market, looking for stability of procurement and logistics services, increase the income of farmers [7].

2) Contract with specialized third party logistics company: Professional third party logistics companies have specialized equipment and logistics distribution network to ensure efficient delivery.

Due to the agricultural product logistics equipment, distribution costs are very high, the use of third party logistics operation to achieve large-scale circulation of agricultural products, reduce unit costs. For example, the third party logistics company cold chain truck, can delivery pork in the morning, and be used to transport other companies of vegetable products in the afternoon, and then effectively reduce the cost [8].

3) End sales and customer service: the use of specialized business platform, specializing in network marketing, to develop customer service.

\section{Use Internet of Things Technology to Achieve}

\section{Products Traceability and Tracking}

In the quality traceability of agricultural products, through the process of production, circulation and sales of agricultural products, the whole process of information perception, transmission, integration and processing, the realization the whole process traceability of agricultural products "from farm to table" [9].

In the aspect of agricultural products logistics, the acquisition and tracking of product information can effectively improve the efficiency of agricultural products in storage and transportation.

In the process of circulation, use sensor devices to perceive the temperature and storage condition of the special goods such as fresh goods, frozen food and so on in the process of transportation, the relevant personnel can make timely information processing, so as to ensure the quality and safety of the goods delivery process [10].

\section{CONCLUSION}

The development of electronic commerce has brought many new models to the circulation of agricultural products. Although the new model overcomes many shortcomings of the traditional circulation pattern, it has many advantages, such as reducing the circulation of agricultural products, shortening the time of circulation, supply and demand information, expanding sales channels and so on. But there are also many problems, such as the coverage of electronic commerce in rural place is not high; in the circulation channels, high repetition rate, high circulation costs, cannot win depending on the supply chain, the degree of information is not high enough.

This paper is aimed at the problem of the circulation pattern of agricultural products electronic commerce, put forward the countermeasures from the government, enterprises, supply chain and the Internet of things and other aspects, hope to promote the circulation of agricultural products in China, to optimize the distribution of agricultural products in China.

\section{REFERENCES}

[1] Yang Lingli, "The enlightenments of circulation patterns of agricultural products in developed countries to China's" $[\mathrm{J}]$, Agricultural Economy, March 2014, pp.125-126

[2] Qi Fang, Zheng Tingting, Pan Fengchai, "Analysis of agricultural products logistics mode based on the third party e-commerce platform"[J]. Agricultural Economy, November 2012, pp. 106-108.

[3] Xing Jiangbo, "E-commerce environment of fresh agricultural products logistics city distribution network optimization" [J], Dalian Maritime University, master's thesis, 2012. pp. 174.

[4] Wang Yan, "On the problem of promoting agricultural product sales by Internet Marketing"[J], Agricultural Economy, February 2014, pp.114-115.

[5] Zhang Xicai, "The current situation, problems and countermeasures of e-commerce into the countryside" [J], Agricultural Economics and Management, March 2015, pp.71-79.

[6] Sun Yi, "Agricultural products network marketing strategy analysis on e-commerce environment" [J], Agricultural Economy, December 2014, pp.139-140

[7] $\mathrm{Hu}$ Yujie, "Based on the electronic commerce platform for the construction of agricultural products circulation chain research" [J], Agricultural Economy and Technology, August 2015, pp. 113-114.

[8] Zhang Ya, "Research of agricultural product sales model based on the mobile e-commerce" [J], Agricultural Economy, June 2013, pp.117-118.

[9] Hong Tao, Zhang Chuanlin, “2014-2015 China's agricultural products e-commerce development report"[J], China's BusinessTheory, May 2015, pp. 44-54.

[10] Wang Xifu, "the Internet of things and smart logistics" [M], Tsinghua University press, 2014. pp.134-137. 